\title{
Combined use of free light chain and heavy/light chain ratios allow diagnosis and monitoring of patients with monoclonal gammopathies: Experience of a single institute, with three exemplar case reports
}

\author{
ALFREDO GAGLIARDI $^{1}$, CLAUDIO CARBONE ${ }^{2}$, ANGELA RUSSO $^{2}$, ROSANNA CUCCURULLO $^{1}$, \\ ANNA LUCANIA $^{1}$, PAOLA DELLA CIOPPA ${ }^{1}$, GABRIELLA MISSO ${ }^{3}$, \\ MICHELE CARAGLIA $^{3}$, CATELLO TOMMASINO ${ }^{2}$ and LUCIA MASTRULLO ${ }^{1}$ \\ Complex Operative Units of ${ }^{1}$ Hematology and ${ }^{2}$ Clinical Pathology, San Gennaro Hospital, \\ Naples 1 Local Health Center, I-80135 Naples, Italy; ${ }^{3}$ Department of Biochemistry, Biophysics \\ and General Pathology, Second University of Naples, I-80138 Naples, Italy
}

Received April 6, 2016; Accepted June 2, 2016

DOI: $10.3892 / 01.2016 .4965$

\begin{abstract}
Monoclonal gammopathies are characterized by serum monoclonal component (MC) plus an intact immunoglobulin and a free light chain (FLC), or a combination of both. The measurement of FLC with Freelite ${ }^{\circledR}$ is the standard practice recommended by International Myeloma Working Group guidelines. Recently, Hevylite ${ }^{\circledR}$ heavy/light chains (HLC) assays were introduced to specifically target junctional epitopes between the heavy and light chains of intact immunoglobulins, allowing the independent quantification of the involved (MC) and uninvolved (polyclonal immunoglobulin background) HLC isotype. Between January 2012 and March 2014, 90 patients were examined: 49 multiple myeloma (MM), 6 smoldering MM (SMM) and 35 monoclonal gammopathy of undetermined significance (MGUS). Of these 90 patients, 300 samples were collected at different times. The diagnostic and monitoring contribution of Hevylite A and G assays was assessed in all 90 patients examined. Additionally, 3 representative cases were selected. The Hevylite absolute values and ratio demonstrated high sensitivity and specificity with respect to serum protein electrophoresis and serum immunofixation. The combined use of Hevylite A and $\mathrm{G}$ with Freelite was particularly useful in dubious cases with more than one $\mathrm{MC}$ or with co-migrating components, as well as in the course of monitoring to assess the independent change of FLC and HLC, possibly reflecting the presence of
\end{abstract}

Correspondence to: Dr Alfredo Gagliardi, Complex Operative Unit of Hematology, San Gennaro Hospital, Naples 1 Local Health Center, Via San Gennaro dei Poveri 25, I-80135 Naples, Italy E-mail: gagliardialfredo@inwind.it

Key words: monoclonal gammopathy of undetermined significance, smoldering myeloma, multiple myeloma, free light chain, heavy/light chain, serum protein electrophoresis, serum immunofixation clonal heterogeneity in the cohort. From this study, it can be concluded that FLC and HLC are independent, useful markers to monitor the MC and to assess with greater specificity and sensitivity the effect of therapy, thereby providing clinical support. Further studies are required to assess the prognostic potential of Hevylite in MGUS and SMM.

\section{Introduction}

Monoclonal gammopathies are characterized by the presence of a serum monoclonal component (MC) produced by clonal plasma cells. The MC can be an intact immunoglobulin alone or in combination with a free light chain (FLC), either $\kappa$ or $\lambda(1,2)$.

Precise and accurate MC quantification is one of the key parameters required to discriminate between monoclonal gammopathy of undetermined significance (MGUS), multiple myeloma (MM) and smoldering MM (SMM) $(1,2)$. The monitoring of $\mathrm{MC}$ levels provides indications of the response to therapy and, with the advent of immunomodulatory drugs, $\mathrm{MC}$ quantification has also been identified as a quick method to assess the depth of response, providing prominent prognostic information $(3,4)$.

Traditionally, quantification and characterization of the $\mathrm{MC}$ relies on serum protein electrophoresis (SPEP) and serum immunofixation (sIFE), respectively. A lack of standardization, limited sensitivity and subjectivity, to a certain extent, are the main limitations of these techniques $(5,6)$.

The introduction of Freelite ${ }^{\circledR}$ (The Binding Site Group Ltd., Birmingham, UK) for the automatic nephelometric/turbidimetric measurement of serum (s)FLC in 2001 (7) radically changed the diagnostic procedure in clinical practice, and FLC is now an established tool for hematological diagnostics (8-10).

More recently, a new assay was introduced: Hevylite ${ }^{\circledR}$ (The Binding Site Group Ltd.) for heavy/light chain (HLC) quantification. Hevylite targets the junctional epitopes, allowing the measurement of couples of immunoglobulin (Ig)' $\kappa / \operatorname{Ig}^{\prime} \lambda(\mathrm{IgG} \kappa$, 
$\operatorname{Ig} \mathrm{G} \lambda, \operatorname{Ig} \mathrm{A} \kappa, \operatorname{Ig} \mathrm{A} \lambda, \operatorname{Ig} \mathrm{M} \kappa$ and $\operatorname{Ig} \mathrm{M} \lambda)$, thus, providing novel insight into the quantification and characterization of $\mathrm{MC}$ (11).

FLC and HLC assays have routinely been performed at San Gennaro Hospital (Naples 1 Local Health Center, Naples, Italy) for the follow-up of MM patients. The current study demonstrates the clinical utility of these assays, providing 3 examples of their combined use and displaying the advantages with respect to traditional tools.

\section{Patients and methods}

Patient selection and frequency of monitoring with FLC and HLC. Between January 2012 and March 2014, 300 samples were collected from 90 patients (49 MM, 6 SMM and 35 MGUS) treated in the Complex Operative Unit (U.O.C.) of Hematology of San Gennaro Hospital (Naples 1 Local Health Center). The mean age was 69.14 years, and the $49 \mathrm{MM}$ patients were split into $21 \mathrm{IgG \kappa}$ MM, $16 \mathrm{IgG} \lambda \mathrm{MM}, 6 \mathrm{Ig} \mathrm{A} \kappa$ MM, 3 IgA $\lambda$ MM and 3 light-chain MM (LCMM).

FLC and HLC were repeated every 3 months in MM patients under treatment, to assess their response to therapy. SMM patients were monitored every 6 months, whereas MGUS patients were monitored every 6-12 months, depending on their risk assessment. MGUS and SMM were re-assessed by the clinicians every 4 months.

Every month, a clinical evaluation was performed on the MM patients under chemotherapy; during follow-up they were monitored every 3 months.

This study was approved by the Ethical Committee of San Gennaro Hospital and written informed consent was obtained from all patients.

Treatment options. The MM patients received different treatment protocols. In total, 7 patients were eligible to receive autologous stem cell transplantation (ASCT); 3 received a bortezomib, thalidomide and dexamethasone regimen and the remaining 4 received a bortezomib, doxorubicin and dexamethasone (PAD) regimen. Among the remaining 42 patients, 16 received a melphalan, prednisone and bortezomib (MPV) regimen and 3 an MP regimen, while the patients who experienced relapse received lenalidomide and dexamethasone (Rd; 19 patients) or bortezomib and dexamethasone (VD; 4 patients) therapy. In detail, the therapeutic regimens were as follows: i) $1.3 \mathrm{mg} / \mathrm{m}^{2}$ bortezomib (Velcade ${ }^{\circledR}$ ) on days $1,4,8$ and $11,50 \mathrm{mg} /$ day thalidomide on days $1-14,100 \mathrm{mg} /$ day thalidomide on days $15-28$, and $40 \mathrm{mg}$ dexamethasone on days 1-4 and 8-11 (4 cycles every 28 days); ii) PAD regimen: $1.3 \mathrm{mg} / \mathrm{m}^{2}$ bortezomib on days $1,4,8$ and $11,30 \mathrm{mg} / \mathrm{m}^{2}$ liposomal doxorubicin $\left(\right.$ Caelix ${ }^{\circledR}$ ) on day 1 , and $20 \mathrm{mg}$ dexamethasone on days 1-2, 4-5, 8-9 and 11-12 (6 cycles every 28 days); iii) MPV regimen: $1.3 \mathrm{mg} / \mathrm{m}^{2}$ bortezomib on days $1,8,15$ and 22 , $9 \mathrm{mg} / \mathrm{m}^{2}$ melphalan on days $1-4$, and $60 \mathrm{mg} / \mathrm{m}^{2}$ prednisone on days $1-4$ (9 cycles every 28 days); iv) MP regimen: $9 \mathrm{mg} / \mathrm{m}^{2}$ melphalan on days $1-4$ and $60 \mathrm{mg} / \mathrm{m}^{2}$ prednisone on days $1-4$ (6 cycles every 28 days); v) Rd regimen: $25 \mathrm{mg}$ lenalidomide on days 1-21, and $20 \mathrm{mg}$ dexamethasone on days 1-4, 9-12 and 17-20 (every 28 days until to progression); and vi) VD regimen: $1.3 \mathrm{mg} / \mathrm{m}^{2}$ bortezomib on days $1,4,8$ and 11 , and $40 \mathrm{mg}$ dexamethasone on days $1,4,8$ and 11 (6 cycles every 28 days).
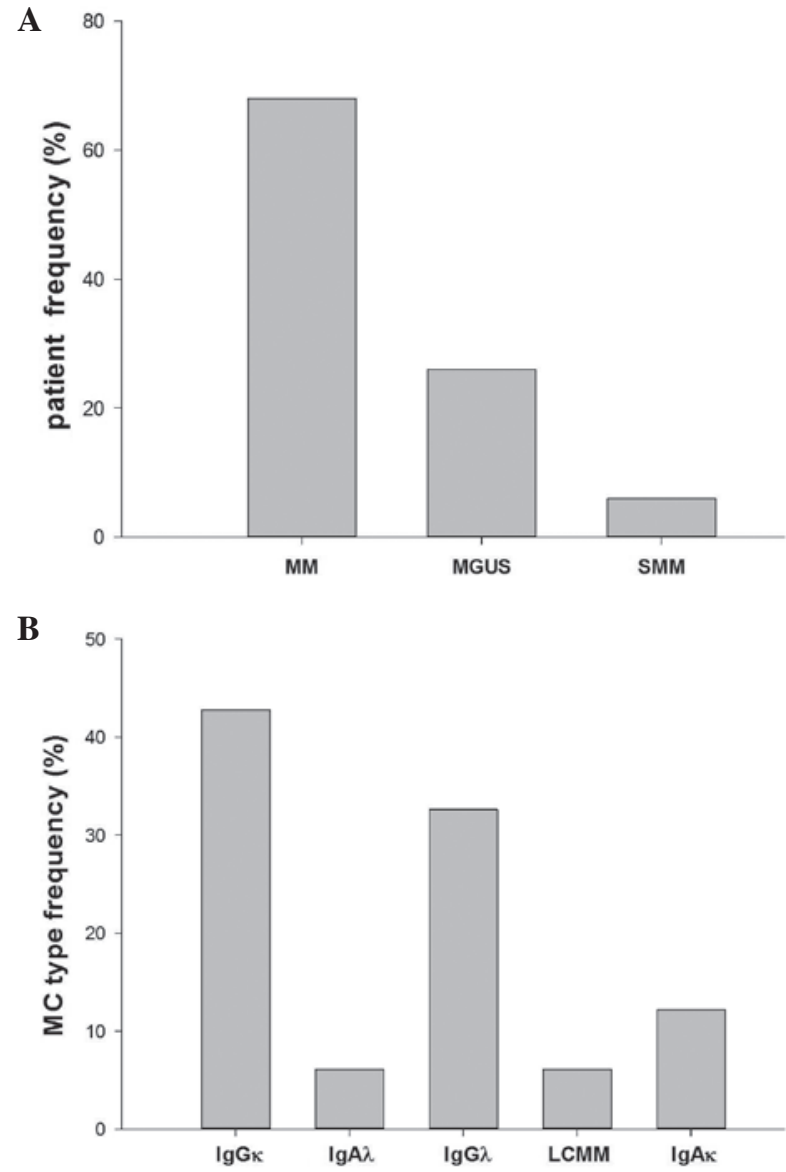

Figure 1. MGUS, MM and SMM patient frequency and MC type distribution in the study population. (A) Percentage of patients with MGUS, MM and SMM, accounting for 6, 26 and 68, of the population, respectively. (B) $\mathrm{MC}$ type frequency in the population, consisting of $42.8 \% \mathrm{IgG \kappa}, 6.1 \%$ $\operatorname{IgA} \lambda, 32.6 \% \operatorname{IgG} \lambda, 6.1 \% \mathrm{LCMM}$ and $12.2 \% \operatorname{IgA\kappa }$ MM patients. MM, multiple myeloma; SMM, smoldering MM; MGUS, monoclonal gammopathy of undetermined significance; $\mathrm{Ig}$, immunoglobulin; MC, monoclonal component.

Laboratory tests. Serum samples were analyzed with the standard diagnostic work up for MC (12-14), and stored at $-20^{\circ} \mathrm{C}$. sPEP with $0.8 \%$ agarose gel was used for separating $\beta 1 / \beta 2$ bands, and black staining was analyzed by scanning densitometry (Hydrasys 2; Sebia, Lisses, France) to quantify the CM in $\%$ and $\mathrm{g} / \mathrm{dl}$. sIFE and urine IFE on agarose gel with acid violet staining (Sebia) were employed for confirmation of clonality and subsequent typing.

Total IgA, IgG and IgM (Roche Diagnostics, Basel, Switzerland) were measured using serum immunifixation, as well as azotemia and creatinemia for the assessment of renal function.

Freelite and Hevylite (The Binding Site Group Ltd.) assays were used for FLC determination and independent HLC isotype quantification, respectively. The Hevylite assay relies on the targeting of junctional epitopes between the heavy and light chains of intact Igs. The associated measurements were performed on turbidimetric platform SPAplus ${ }^{\circledR}$ (The Binding Site Group Ltd.).

Measurements of these parameters were used to derive $\operatorname{IgG\kappa } / \operatorname{IgG} \lambda$, which were compared with reference ranges. A HLC ratio (HLCr) outside of the reference range was considered to be indicative of a clonal process. 


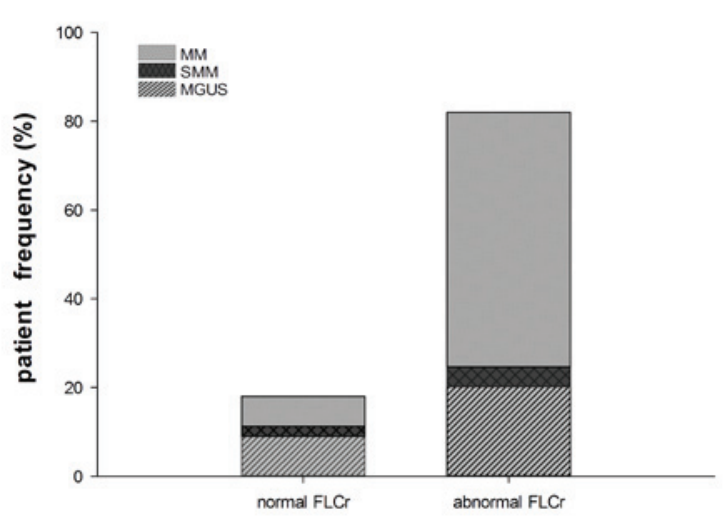

Figure 2. Abnormality of FLCr in the overall population, and MGUS, SMM and MM frequency. FLC abnormality was present in $82 \%$ of all patients; among these samples, $69.9 \%$ were MM patients, $24.6 \%$ were MGUS patients and $5.5 \%$ were SMM patients. With regard to the remaining $18 \%$ of patients without FLCr abnormality, 37.5\% were MM patients, 50\% were MGUS patients and $12.5 \%$ were SMM patients. MM, multiple myeloma; SMM smoldering MM; MGUS, monoclonal gammopathy of undetermined significance; FLC, free light chain; FLCr, FLC ratio.

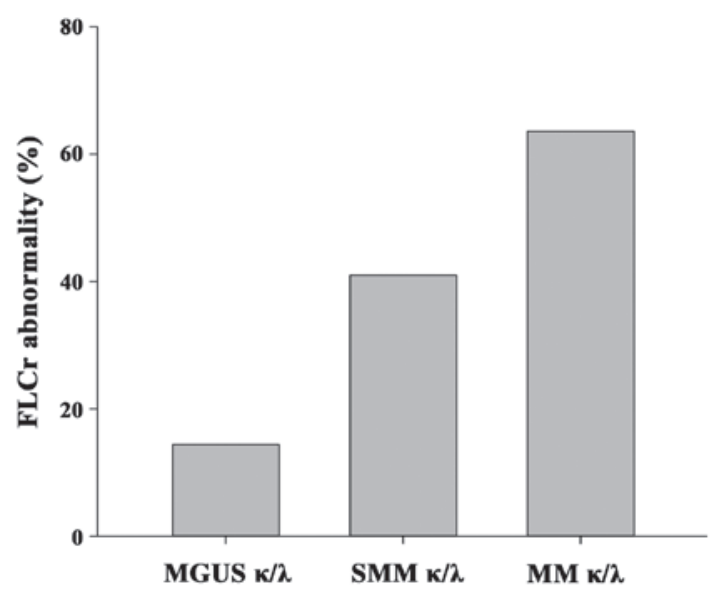

Figure 3. $\kappa / \lambda$ FLCr abnormality in the three types of patients: MGUS, SMM and MM. $\kappa / \lambda$ ratio abnormality in the three categories of MGUS, SMM and MM patients, accounted for $14.4,41.0$ and $63.6 \%$ of cases, respectively. MM, multiple myeloma; SMM, smoldering MM; MGUS, monoclonal gammopathy of undetermined significance; FLCr, free light chain ratio.

Patients were categorized using FLC ratio (FLCr) prognostic values, which were broadly identified using receiver operator characteristic analysis with final cut-offs being identified by trial and error.

\section{Results}

MGUS, MM and SMM frequency. The study population consisted of $49 \mathrm{MM}$ patients (37 IgG, $9 \mathrm{IgA}$ and 3 LCMM), 35 MGUS and 6 SMM. Patients were selected from the population treated at the U.O.C. of Hematology of San Gennaro Hospital. This accounts for the lower percentage of MGUS with respect to MM, as low-risk MGUS patients are usually referred to a general practitioner.

In the study population, the majority of MC cases were $\mathrm{IgG \kappa}$, followed by $\operatorname{IgG} \lambda$ at $30 \%$ and $\operatorname{IgA} \kappa$ at $11 \%$. Only a small percentage $(5 \%)$ of LCMM was found (Fig. 1).
FLC abnormality was present in $82 \%$ of all patients (MM, SMM and MGUS) when considering the first sample received, which was regarded as the diagnostic sample (Fig. 2).

In total, $69.9 \%$ of the samples were MM patients, $24.6 \%$ were MGUS patients and 5.5\% were SMM patients; however, care must be taken when assessing these results due to the limited number of SMM patients (6).

Notably, $70 \%$ of the intact immunoglobulin MM (IIMM) samples had an abnormal FLC (15), thus supporting the use of FLCr as an additional marker to diagnose and monitor IIMM.

FLCr abnormality: Distribution across MGUS, SMM and $M M$ patients. The FLCr is an important indicator of FLC pair suppression, with prominent prognostic meaning in MM patients at diagnosis and in the course of treatment (9); a high degree of abnormality correlates with reduced overall survival and progression-free survival times (16). In the present study population, ratio abnormality was compared in the three categories of MGUS, SMM and MM (Fig. 3), to assess the level of pair suppression. The majority of the patients had an $\mathrm{IgG \kappa}$ $\mathrm{MC}$; therefore, this type of patient was focused upon.

The mean value of the $\mathrm{IgG \kappa} / \mathrm{IgG} \lambda$ ratios was obtained, and a rising trend of the FLCr level was found in the three categories, suggesting that the severity of the FLC imbalance could be associated with overt disease.

\section{Selected clinical cases}

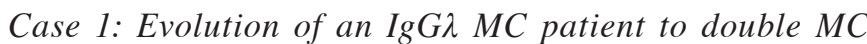
and then LCMM (Fig. 4). A 60-year-old man was diagnosed with $\operatorname{IgG} \lambda \mathrm{MM}$ in March 2006 and received VAC $\left(2 \mathrm{mg} / \mathrm{m}^{2}\right.$ vincristine on day $1,30 \mathrm{mg} / \mathrm{m}^{2}$ liposomal doxorubicin on day 2 , $100 \mathrm{mg}$ cyclofosfamide on days 1-4; 6 cycles every 28 days) at the Hematology Unit of S. Giovanni Bosco Hospital (Naples, Italy). In February 2009, the patient commenced therapy with the Rd regimen at the U.O.C. of Clinical Pathology of San Gennaro Hospital, and was routinely monitored with sPEP, sIFE and FLC.

From March 2012, HLC was introduced at the U.O.C. of Clinical Pathology of San Gennaro Hospital and was used together with FLC.

In October 2012 the patient had a small $\operatorname{IgG\lambda } \mathrm{MC}(4.7 \mathrm{~g} / \mathrm{l})$, quantified by sPEP; FLC $\lambda$ (620 mg/l) was significantly above the normal range (NR) of 5.7-26.3 $\mathrm{mg} / \mathrm{l}$ and the FLCr was highly abnormal at 0.01 (NR, 0.26-1.65). IgG $\lambda$ HLC (4.26 g/l)

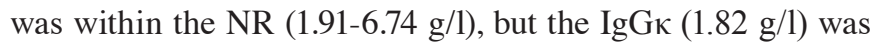
below NR (3.84-12.07 g/l), thus the IgG HLCr abnormality was consistent with sIFE. This suggested the presence of persistent monoclonality even with relatively low MC levels, aiding in the assessment of a small MC together with the response to therapy.

In February 2013, a secondary small $\operatorname{IgG} \lambda$ MC was identified through sIFE and SPEP, and FLC $\lambda$ increased had to $1,049 \mathrm{mg} / \mathrm{l}$. By contrast, IgG $\lambda$ HLC levels were decreased with respect to the previous time point $(3.23 \mathrm{~g} / \mathrm{l})$, while $\mathrm{IgG \kappa}$ HLC (1.88 g/l) remained below the NR. HLC pair suppression assisted in identifying monoclonality even in the presence of small electrophoretic peaks that were hardly quantifiable with SPEP.

In April 2013, therapy was suspended due to a vertebral collapse requiring kyphoplasty, as well as severe anemia requiring blood transfusions. 
A
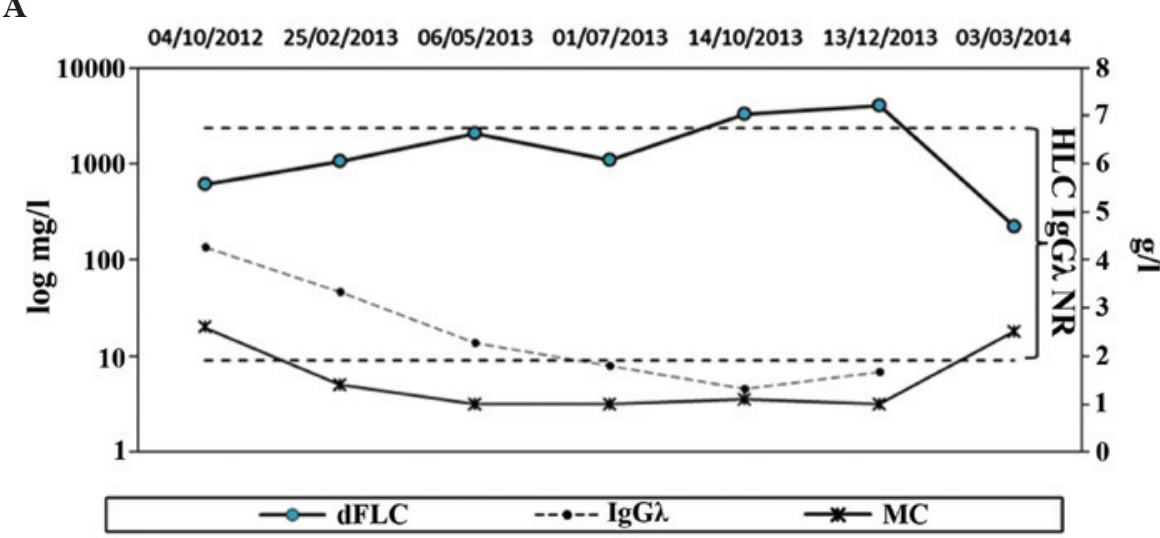

\begin{tabular}{|c|c|}
\hline October 2012 & February 2013 \\
\hline HLC G & HLC G \\
\hline $\operatorname{IgG\kappa } \underline{1.82(\mathrm{~g} / \mathrm{l})}$ & $\operatorname{IgG\kappa } \underline{1.88(\mathrm{~g} / 1)}$ \\
\hline $\mathrm{IgG} \lambda .4 .26(\mathrm{~g} / \mathrm{l})$ & $\operatorname{IgG} \lambda \underline{3.23(\mathrm{~g} / 1)}$ \\
\hline Ratio $\underline{0.43}$ & Ratio $\underline{0.56}$ \\
\hline FLC & FLC \\
\hline FLСк $6.73 \mathrm{mg} / \mathrm{l}$ & FLCк $4.1 \mathrm{mg} / \mathrm{l}$ \\
\hline FLC $\lambda \underline{620 \mathrm{mg} / 1}$ & FLC $\lambda \underline{1049 \mathrm{~m}}$ \\
\hline Ratio 0.01 & Ratio 0.003 \\
\hline
\end{tabular}

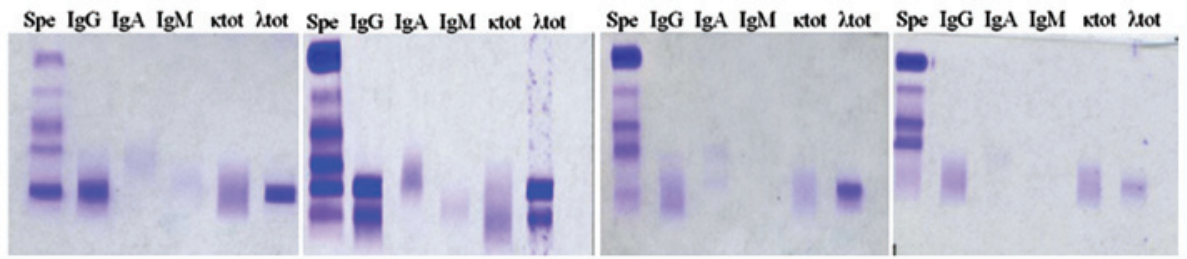

Figure 4. Case 1: Hevylite ${ }^{\circledast} \mathrm{G}$ allowed quantification of the primary and secondary MC. (A) Hevylite G and Freelite ${ }^{\circledast}$ absolute values and ratio, and (B) immunofixation in an $\operatorname{IgG} \lambda \mathrm{MM}$ patient. As the intact immunoglobulin clone appeared to respond to therapy, with normalization of HLC G values, FLCs did not ever normalize, suggesting the presence of a secondary, independent clone of light chain-producing plasma cells, which prompted a change of treatment and autologous stem cell transplantation. Underlined values are outside the NR. HLC, heavy/light chains; FLC, free light chain; Ig, immunoglobulin; MC, monoclonal component; dFLC, difference between FLC $\kappa$ and FLC $\lambda$; NR, normal range; Spc, serum protein components; tot, total.

When the patient returned in October 2013, although HLCr was restored to within the NR, in agreement with the sIFE, the $\operatorname{IgG\kappa }$ and $\operatorname{IgG} \lambda$ levels were below the NR. As MC disappeared in response to therapy, with normalization of Hevylite values and ratio, Freelite never normalized and emerged a secondary clone producing free light chains [light chain escape (LCE)]. FLC $\lambda$ reached $3,297 \mathrm{mg} / \mathrm{l}$ and the patient was diagnosed with LCMM. Treatment with the PAD regimen was then commenced and the patient was eligible for ASCT. Double ASCT was performed in another center prior to returning to the San Gennaro Hospital in March 2014. A marked reduction in FLC $\lambda$ to $230 \mathrm{mg} / \mathrm{l}$ was observed, which was abnormal but significantly lower with respect to the previous values.

For this patient, the combined monitoring of FLC and HLC supplied more detailed information compared with sPEP and sIFE. At the most recent follow-up in June 2016, the patient had commenced therapy with pomalidonmide (4 $\mathrm{mg}$ daily for 21 days, every 28 days) and exhibited stable disease.

Case 2: FLC and HLC persistent abnormality correctly identifies monoclonality of MCs in the presence of secondary clones and predicts clinical relapse (Fig. 5). A 78-year-old woman was diagnosed with $\operatorname{Ig} \mathrm{A} \lambda$ and FLC $\lambda$ MM in October 2012. The IgA $\lambda$ MC, estimated by sPEP, was $22.4 \mathrm{~g} / \mathrm{l}$, while FLC $\lambda$ was $258.6 \mathrm{mg} / \mathrm{l}$. The patient underwent 5 cycles of therapy with MP. In November 2012, a partial response was obtained and the sPEP did not show any monoclonal peak. Hevylite $\operatorname{Ig} A \kappa$ and $\operatorname{Ig} A \lambda$ were within the NR; importantly, the HLCr was also normal at this time point, suggesting that patient had responded to therapy. However, FLC $\lambda(48 \mathrm{mg} / \mathrm{l})$ and FLCr $(0.01)$ remained above the NR, thus indicating the presence of residual disease. The shorter FLC half-time compared with IgA meant that an earlier FLC response was expected with respect to intact Igs. Therefore, this could be suggestive of clonal heterogeneity with coexisting FLC and HLC clones, and possibly a diverse sensitivity to the chemotherapy agent.

The patient was constantly monitored and, in June 2013, the sPEP profile suggested the reappearance of an MC visible in the $\gamma$ zone, confirmed by sIFE as IgA $\lambda$. Densitometry measurement of the MC indicated a $5.8 \mathrm{~g} / \mathrm{l}$ peak, whereas $\operatorname{Ig} \mathrm{A} \lambda$

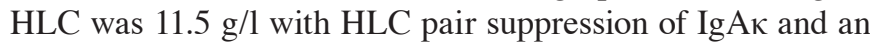
altered HLC A ratio. The Freelite ratio did not normalize and in September 2013, the patient experienced a clinical relapse, revealed by the MC increasing to $11.8 \mathrm{~g} / \mathrm{l}$ and an $\operatorname{IgA} \lambda$ HLC level amounting to $15.3 \mathrm{~g} / \mathrm{l}$. Relapse was confirmed during follow-up. The patient received 6 cycles of the VD regimen, but monitoring with SPEP was not reliable, as the polyclonal 
A

B

November 2012
HLC A
IgAא $0.73(\mathrm{~g} / \mathrm{l})$
IgA $0.863(\mathrm{~g} / \mathrm{l})$
Ratio 0.85
FLC
FLCK $6.85 \mathrm{mg} / 1$
FLC $\lambda \underline{48 \mathrm{mg} / 1}$
Ratio $\underline{0.14}$
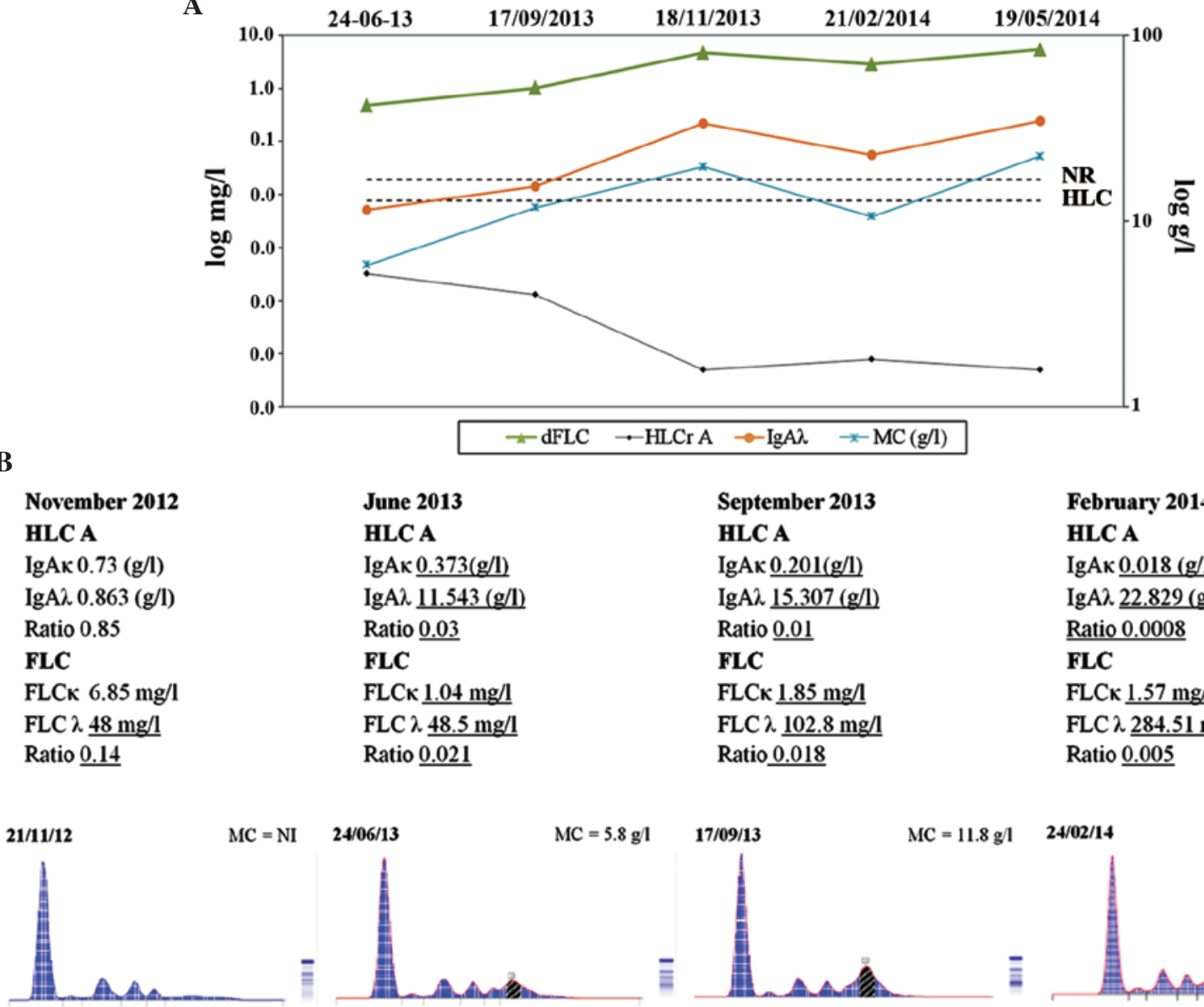

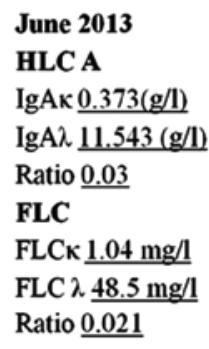

June 2013

$\operatorname{IgA\kappa } \underline{0.373(\mathrm{~g} / \mathrm{l})}$

$\operatorname{IgA\lambda } \underline{11.543(\mathrm{~g} / \mathrm{l})}$

Ratio $\underline{0.03}$

FLC

FLC $\lambda \underline{48.5 \mathrm{mg} / 1}$

$406 / 13$

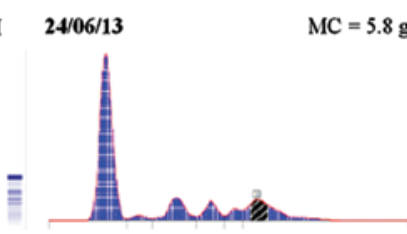

September 2013

HLC A

$\operatorname{IgA\kappa } \underline{0.201(\mathrm{~g} / \mathrm{l})}$

$\operatorname{IgA} \lambda \underline{15.307(\mathrm{~g} / \mathrm{l})}$

Ratio $\underline{0.01}$

FLC

FLCK $1.85 \mathrm{mg} / \mathrm{I}$

FLC $\lambda \underline{102.8 \mathrm{mg} / 1}$

Ratio 0.018
February 2014

HLC A

$\operatorname{IgA\kappa } \underline{0.018(\mathrm{~g} / \mathrm{l})}$

$\operatorname{Ig} A \lambda \underline{22.829(\mathrm{~g} / \mathrm{l})}$

$\underline{\text { Ratio } 0.0008}$

FLC

FLCK $1.57 \mathrm{mg} / 1$

FLC $\lambda \underline{284.51 \mathrm{mg} / 1}$

Ratio $\underline{0.005}$

Figure 5. Case 2: HLC and FLC persistent abnormality predicts relapse prior to the clinical symptoms. (A) Hevylite ${ }^{\circledast}$ and Freelite ${ }^{\circledR}$ absolute values and ratio, and (B) SPEP profile in an IgA $\lambda$ and FLC $\lambda$ MM patient. The high FLC $\lambda(48 \mathrm{mg} / \mathrm{l})$ and FLCr $(0.14)$ levels in November 2012 indicated the presence of residual disease for this patient who previously underwent 5 cycles of therapy with melphalan and prednisone. From June 2013, the sPEP profile showed an MC in the $\gamma$ zone, which appeared increased in the subsequent monitoring. This was accompanied by the observation of FLC and HLC absolute and ratio abnormal values. Underlined values are outside the NR. HLC, heavy/light chains; FLC, free light chain; Ig, immunoglobulin; MC, monoclonal component; dFLC, difference between FLC $\kappa$ and FLC $\lambda$; NR, normal range; HLCr, HLC ratio; sPEP, serum protein electrophoresis; NI, not identified.

Igs in the $\gamma$ zone interfered with an accurate IgA quantification, resulting in an underestimation of the MC $(19.60 \mathrm{~g} / \mathrm{l}$ by sPEP vs. $33.5 \mathrm{~g} / 1 \mathrm{Ig} \mathrm{A} \lambda \mathrm{HLC}$ ). Being unable to quantify the MC by sPEP, HLC A was chosen in combination with Freelite to monitor the patient. In February 2014, a reduction in FLC $\lambda$ and IgA $\lambda$ HLC was observed. However,FLCr and HLCr were highly abnormal, suggesting a significant degree of pair suppression

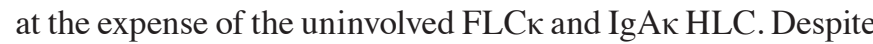
an apparent reduction in the $\mathrm{MC}$ upon densitometric analysis $(10.6 \mathrm{~g} / \mathrm{l})$, the severe degree of pair suppression, revealed by the ratios, suggested that there was no specific tumor killing by chemotherapy. This was confirmed in May 2014 through the observation of an increase of all biochemical disease markers: IgAк. $0.0010 \mathrm{~g} / 1$ (NR 0.57-2.08 g/l); $\operatorname{IgA} \lambda, 23.79 \mathrm{~g} / 1$ (NR 0.44-2.04 g/l); Ratio, 0.0004; FLCк, $1.22 \mathrm{mg} / \mathrm{l}$ (NR 3.3-19.4 mg/l); FLC $\lambda, 298.57 \mathrm{mg} / 1$ (NR 5.71-26.3 mg/l); Ratio, 0.004 . No further treatment was planned and the patient succumbed in July 2014.

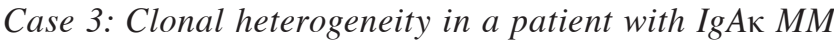
and a secondary MC (Fig. 6). In August 2012, a 77-year-old

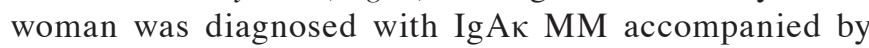
diffuse osteolytic lesions at the U.O.C. of Hematology of San Gennaro Hospital. Treatment commenced with 2 cycles of
PAD, followed by 4 cycles of VD, with 8 monthly injections of zoledronate $(4 \mathrm{mg})$ to prevent skeletal fractures.

The monoclonal IgAк was visible in the $\beta 2$ zone of the sPEP migration pattern, a frequent occurrence with IgA MCs, thus hindering identification and accurate measurement of the monoclonal peak. The patient also exhibited elevated FLCk $(27 \mathrm{mg} / \mathrm{l})$.

In June 2013, the patient suffered from severe anemia and infiltration of the mandibular bone by clonal plasma cells, prompting a change of therapy and the beginning of treatment with the $\mathrm{Rd}$ regimen as salvage treatment.

In September 2013, the Ig Aк (9.08 g/l; NR 0.57-2.0 g/l) and FLCк $(378 \mathrm{mg} / \mathrm{l}$; NR 3.3-19.4 mg/l) levels remained stable and, thus, above the NR. This suggested that no response to therapy occured. At the same time, a secondary MC was identified in the $\gamma$ zone of the migration pattern, and sIFE results were suggestive of IgGк and FLC $\lambda$.

However, when sIFE was compared with FLC and HLC, no abnormality was observed in the $\lambda$ chains and Hevylite ratio $\mathrm{G}(0.76)$ clearly indicated the presence of an $\operatorname{IgG} \lambda$.

This case is a clear example of how sIFE interpretation can be challenging even for a skilled operator when more than one $\mathrm{MC}$ is present, with FLC and intact Igs. 
B

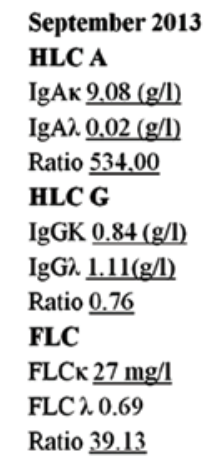

$\operatorname{IgAK} 9.08(\mathrm{~g} / \mathrm{l})$

$\operatorname{IgA} \lambda \underline{0.02(\mathrm{~g} / \mathrm{l})}$

$\operatorname{IgGK} \underline{0.84(\mathrm{~g} / \mathrm{l})}$

$\operatorname{IgG} \lambda \underline{1.11(\mathrm{~g} / \mathrm{l})}$

Ratio $\underline{0.76}$

FLCK $27 \mathrm{mg} / \mathrm{l}$

Ratio 39.13

A
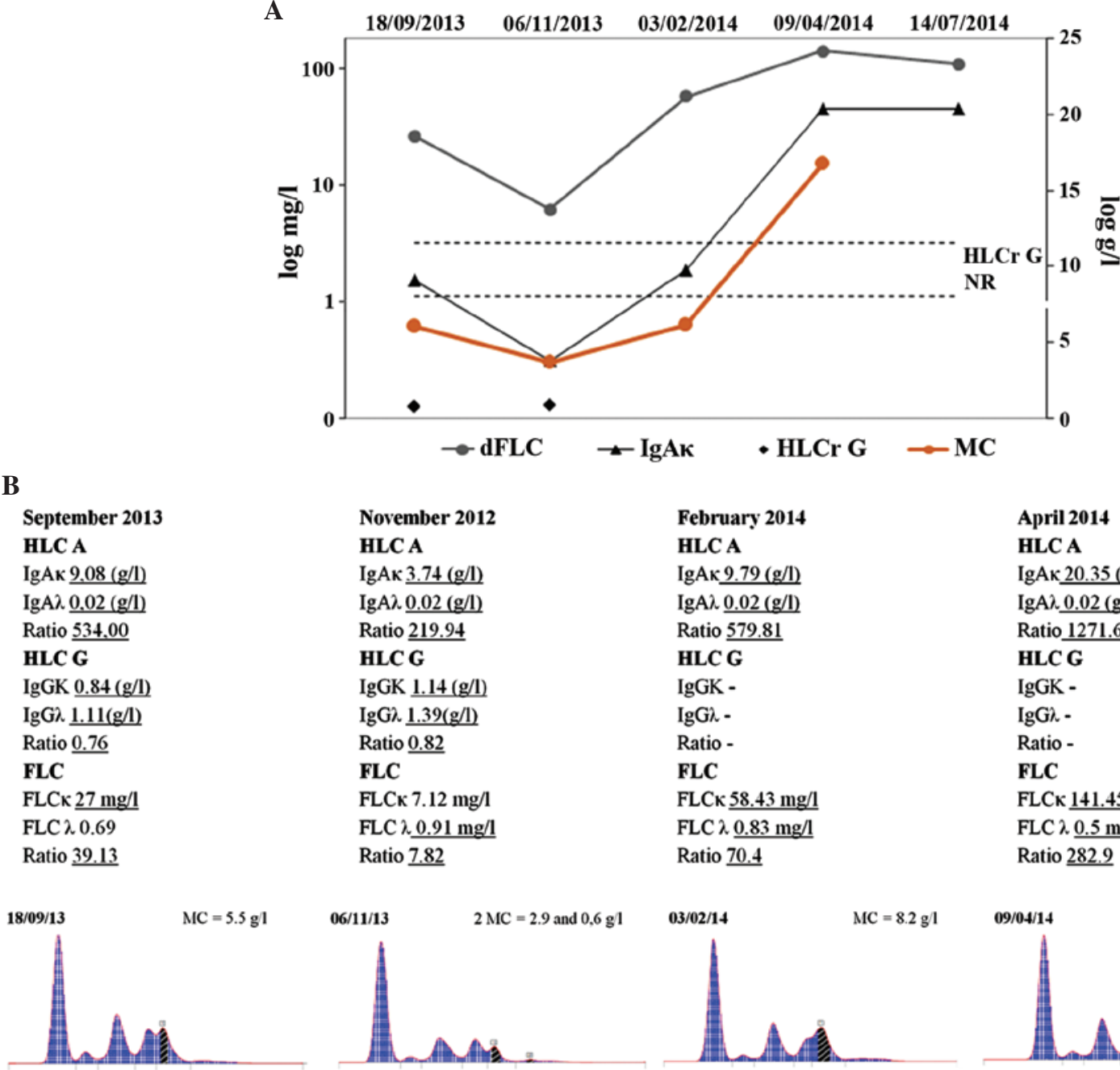

November 2012
HLC A
$\operatorname{IgA\kappa } \underline{3.74(\mathrm{~g} / \mathrm{l})}$
$\operatorname{IgA\lambda } \underline{0.02(\mathrm{~g} / \mathrm{l})}$
Ratio $\underline{219.94}$
HLC G
IgGK $\underline{1.14(\mathrm{~g} / \mathrm{l})}$
$\mathrm{IgG} \lambda \underline{\underline{1.39(\mathrm{~g} / \mathrm{l})}}$
Ratio $\underline{0.82}$
FLC
FLCK $7.12 \mathrm{mg} / 1$
FLC $\lambda \underline{0.91 \mathrm{mg} / 1}$
Ratio $\underline{7.82}$

November 2012

IgAK $3.74(\mathrm{~g} / \mathrm{l})$

$\operatorname{IgA} \lambda \underline{0.02(\mathrm{~g} / \mathrm{l})}$

Ratio 219.94

HLC G

$\mathrm{IgG} \ldots 1.39(\mathrm{~g} / \mathrm{l})$

Ratio $\underline{0.82}$

FLCK $7.12 \mathrm{mg} / 1$

Ratio $\underline{7.82}$

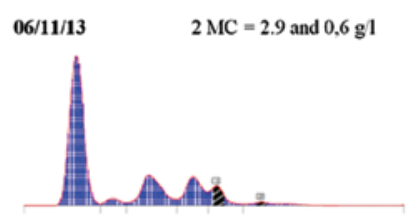

February 2014

HLC A

$\operatorname{IgA\kappa } \underline{9.79(\mathrm{~g} / \mathrm{l})}$

$\operatorname{IgA} \lambda \underline{0.02(\mathrm{~g} / \mathrm{l})}$

Ratio $\underline{579.81}$

HLC G

IgGK -

IgG -

Ratio -

FLC

FLCא $58.43 \mathrm{mg} / \mathrm{l}$

FLC $\lambda \underline{0.83 \mathrm{mg} / \mathrm{l}}$

Ratio $\underline{70.4}$

\author{
April 2014 \\ HLC A \\ $\operatorname{IgAK} \underline{20.35(\mathrm{~g} / \mathrm{A})}$ \\ IgA $\lambda 0.02(\mathrm{~g} / \mathrm{l})$ \\ Ratio $\underline{1271.68}$ \\ HLC G \\ IgGK - \\ $\mathrm{IgG} \lambda$ - \\ Ratio - \\ FLC \\ FLCK $141.45 \mathrm{mg} / \mathrm{l}$ \\ FLC $\lambda \underline{0.5 \mathrm{mg} / \mathrm{l}}$ \\ Ratio $\underline{282.9}$
}

Figure 6. Case 3: HLC and FLC persistent abnormality predicts relapse prior to the clinical symptoms. (A) Hevylite ${ }^{\circledR}$ G and Freelite ${ }^{\circledR}$ absolute values and ratio,

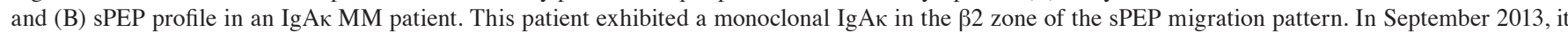
was identified a secondary MC in the $\gamma$ zone of the migration pattern, and Hevylite and Freelite assisted in clarifying the isotypes, allowing for subsequent

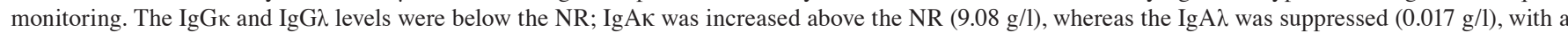
highly abnormal HLC A ratio. In November 2013, there was an improvement in the biochemical parameters of IgGk and IgG $\lambda$, the HLC ratio became closer to the NR, and there was a reduction in AFLC and HLC A. In February 2014, the secondary IgG MC was no longer visible, whereas the IgA HLC and FLC were increased and highly above the NR. HLC A and FLC steadily increased over the next months, until the patient succumbed in October 2014. Underlined values are outside the NR. HLC, heavy/light chains; FLC, free light chain; Ig, immunoglobulin; MC, monoclonal component; dFLC, difference between FLCא and FLC $\lambda$; NR, normal range; HLCr, HLC ratio; sPEP, serum protein electrophoresis.

Hevylite and Freelite assisted in clarifying the isotypes and allowed for subsequent monitoring.

Notably, the IgGK and IgG $\lambda$ levels were below the NR, possibly suggesting a condition of systemic immunoparesis.

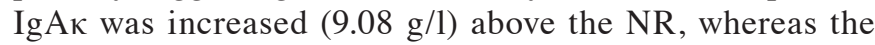
$\operatorname{Ig} A \lambda$ uninvolved chain was suppressed $(0.017 \mathrm{~g} / \mathrm{l})$, with a highly abnormal HLC A ratio of 534.

The patient continued to receive lenalidomide and dexamethasone. At the following time point in November 2013, there was an improvement in the biochemical parameters of $\operatorname{IgG\kappa }$ and $\operatorname{IgG} \lambda$, the HLCr became closer to the NR, and there was a reduction in the difference between FLC $\kappa$ and FLC $\lambda$ (dFLC) and HLC A.

In February 2014, the patient returned to hospital and the secondary MC IgG was no longer visible upon sIFE, whereas

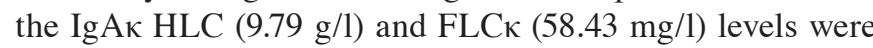
increased and highly above the NR. IgAא HLC (20.35 g/l) and FLCK (141.45 mg/l) steadily increased over the next months despite treatment with the Rd regimen, until the patient succumbed in October 2014.

\section{Discussion}

Accurate quantification of the MC is fundamental for forming a differential diagnosis and to assess the response to therapy (17), as well as to define immune system reconstitution in patients undergoing ASCT (18). Traditional routine tests include sPEP and SIFE, which occasionally lack sensitivity and specificity. On the other side, the current advances in molecular biology and cytogenetics have led to a major breakthrough in the development of newer and highly resolutive technologies, although they are not easily accessible for all patients, thus confirming the requirement for quick, reliable and standardized serum markers (19).

Within this scenario, serum immunoglobulin FLC measurement with polyclonal antisera represents an important diagnostic tool for monitoring patients (8). 
Unlike total light chain assays, Freelite allows separate measurement of sFLC $\kappa$ and $\lambda$, thus allowing the determination of the $\kappa / \lambda$ ratio (FLCr), which serves as a reliable marker of monoclonality that is particularly relevant for a diagnosis (10). On the other hand, concerning the monitoring, it is also important to consider the dFLC and the individual concentrations of involved and uninvolved FLC. The degree of the Freelite ratio abnormality has been associated with disease progres-

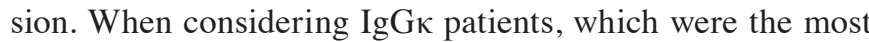
abundant in the present study population, in agreement with previous reports (20), a trend of greater FLC abnormality in MGUS, SMM and MM IgG patients was observed.

FLC is a reliable marker that can be used together with traditional tests to diagnose and monitor all monoclonal gammopathies (21). In the present study, it was observed that the FLCr was abnormal in $82 \%$ of all patients, including SMM and MGUS patients, supporting the use of FLC in LCMM and non-secretory MM monitoring $(22,23)$.

However, the clinical utility is not restricted to these patients. FLCs are also fundamental for IIMM: In $80 \%$ of IIMM, FLC determination is required. As shown in the first case, FLCs were independent markers of disease and allowed identification of LCE (24).

Hevylite has been used since 2012 in San Gennaro Hospital and the current study presents 3 exemplar cases where the introduction of Hevylite, together with Freelite, provided additional information with respect to standard techniques. Similarly to FLC, HLCrs are powerful and sensitive markers of monoclonality, providing novel insight into the balance between the involved and uninvolved Igs $(25,26)$.

Clinical case 1 is a perfect example of how FLC and HLC can be reliable markers of disease, particularly for small MCs. Double MCs can be difficult to evaluate since the migration patterns could prevent accurate quantifications (27). At the same time, total Igs cannot distinguish between the MC and the polyclonal background (28). Hevylite, in this case, allowed the quantification of the $\operatorname{IgG} \lambda \mathrm{MC}$ and confirmed the disappearance of the $\mathrm{IgG}$ component.

The combined use of FLC and HLC is emerging as a novel strategy to detect $\mathrm{MC}$ and to enable better monitoring of patients, allowing the depth of response to treatment as well as the minimal residual disease (MRD) to be assessed; it can also be used to detect relapse in MM patients (29). Clinical case 2 demonstrated Freelite sensitivity for residual disease, in spite of clinical remission and low MC levels assessed by SPEP. In this case, the MC was not accurately quantifiable with sPEP, but only Hevylite allowed precise MC measurement and also identified its reappearance, anticipating the clinical relapse. FLC $\lambda$ and FLCr did not normalize, thus suggesting persistence of the disease, and Hevylite $\mathrm{G}$ also became abnormal several months prior to clinical relapse.

A noteworthy point of discussion within the clinical community is the requirement for earlier indicators of relapse and reliable markers of MRD that could support the intention to treat (30). In clinical case 2, the persistent FLCr abnormality and the early identification of relapse by HLCr, with respect to clinical symptoms, can be taken as an example of how a careful and evidence-based selection of novel markers could lead to a change in the paradigm of clinical practice (31).
The scientific evidence in support of HLC shows that it has greater sensitivity, providing quantitative results also in the absence of an MC detectable by sPEP; in addition, it can clarify dubious sIFE patterns $(32,33)$.

The third case presented in the current study is a clear example of the advantages of Hevylite and Freelite over sIFE; this case also highlights the usefulness of these assays for laboratory specialists and clinicians. With regard to their use in the laboratory, these techniques could change the usual way of monitoring patients, possibly replacing traditional tests and providing more rapid, quantitative and qualitative results all in one. The potential clinical use of Hevylite and Freelite could be even wider and have a strong impact on prognosis $(34,35)$.

As the attention focused on these novel biomarkers increases, the most pressing issue will be their application in the improvement of patient management.

Potentially, HLC could become part of a panel of parameters required to support the intention to treat prior to the observation of a severe clonal expansion accompanied by the aggravation of symptoms. All these parameters move in the same direction as the recently updated International Myeloma Working Group criteria for MM diagnosis, introducing the concept of 'myeloma defining events', which are expected to become as important as CRAB (calcium elevated, renal failure, anemia, bone lesions) symptoms $(10,36)$. At the same time, the possibility to closely monitor the response to therapy, or the lack thereof, could provide indications to support a change of treatment or an adjustment in the frequency of monitoring.

Certainly, more evidence will be required prior to the implementation of such a paradigmatic change. However, in our experience, the benefits of Freelite and Hevylite monitoring in patients with monoclonal gammopathies are already visible. In this regard, the present clinical cases, clearly demonstrating the positive advantages of HLC and FLC assessment with respect to traditional tests, could provide valid support in illustrating the beneficial impact of these assays for the clinical and laboratory management of MM patients.

\section{References}

1. Durie BG, Kyle RA, Belch A, Bensinger W, Blade J, Boccadoro M, Child JA, Comenzo R, Djulbegovic B, Fantl D, et al; Scientific Advisors of the International Myeloma Foundation: Myeloma management guidelines: A consensus report from the Scientific Advisors of the International Myeloma Foundation. Hematol J 4: 379-398, 2003.

2. Kyle RA, Durie BG, Rajkumar SV, Landgren O, Blade J, Merlini G, Kröger N, Einsele H, Vesole DH, Dimopoulos M, et al; International Myeloma Working Group: Monoclonal gammopathy of undetermined significance (MGUS) and smoldering (asymptomatic) multiple myeloma: IMWG consensus perspectives risk factors for progression and guidelines for monitoring and management. Leukemia 24: 1121-1127, 2010.

3. Aritaka N, Ichikawa K, Nakamura H, Yasuda H, Ogura K, Matsumoto T, Komatsu N and Hirano T: Attainment of a stringent complete response in multiple myeloma with thalidomide monotherapy. Intern Med 51: 2781-2783, 2012.

4. Alhaj Moustafa M, Rajkumar SV, Dispenzieri A, Gertz MA, Lacy MQ, Buadi FK, Hwa YL, Dingli D, Kapoor P, Hayman SR et al: Utility of serum free light chain measurements in multiple myeloma patients not achieving complete response to therapy. Leukemia 29: 2033-2038, 2015.

5. Katzmann JA, Kyle RA, Benson J, Larson DR, Snyder MR, Lust JA, Rajkumar SV and Dispenzieri A: Screening panels for detection of monoclonal gammopathies. Clin Chem 55: 1517-1522, 2009. 
6. Murray DL, Ryu E, Snyder MR and Katzmann JA: Quantitation of serum monoclonal proteins: Relationship between agarose gel electrophoresis and immunonephelometry. Clin Chem 55: 1523-1529, 2009.

7. Bradwell AR, Carr-Smith HD, Mead GP, Tang LX, Showell PJ, Drayson MT and Drew R: Highly sensitive, automated immunoassay for immunoglobulin free light chains in serum and urine. Clin Chem 47: 673-680, 2001.

8. Dispenzieri A, Kyle R, Merlini G, Miguel JS, Ludwig H, Hajek R, Palumbo A, Jagannath S, Blade J, Lonial S, et al; International Myeloma Working Group: International Myeloma Working Group guidelines for serum-free light chain analysis in multiple myeloma and related disorders. Leukemia 23: 215-224, 2009.

9. Rajkumar SV, Harousseau JL, Durie B, Anderson KC, Dimopoulos M, Kyle R, Blade J, Richardson P, Orlowski R, Siegel D, et al; International Myeloma Workshop Consensus Panel 1: Consensus recommendations for the uniform reporting of clinical trials: Report of the International Myeloma Workshop Consensus Panel I. Blood 117: 4691-4695, 2011.

10. Rajkumar SV, Dimopoulos MA, Palumbo A, Blade J, Merlini G, Mateos MV, Kumar S, Hillengass J, Kastritis E, Richardson P. et al: International Myeloma Working Group updated criteria for the diagnosis of multiple myeloma. Lancet Oncol 15: e538-e548, 2014.

11. Bradwell AR, Harding SJ, Fourrier NJ, Wallis GLF, Drayson MT, Carr-Smith HD and Mead GP: Assessment of monoclonal gammopathies by nephelometric measurement of individual immunoglobulin kappa/lambda ratios. Clin Chem 55: 1646-1655, 2009.

12. Guidelines Working Group of UK Myeloma Forum; British Committee for Standards in Haematology, British Society for Haematology: Guidelines on the diagnosis and management of AL amyloidosis. Br J Haematol 125: 681-700, 2004.

13. Bird J, Behrens J, Westin J, Turesson I, Drayson M, Beetham R, D'Sa S, Soutar R, Waage A, Gulbrandsen N, et al; Haemato-oncology Task Force of the British Committee for Standards in Haematology, UK Myeloma Forum and Nordic Myeloma Study Group: UK Myeloma Forum (UKMF) and Nordic Myeloma Study Group (NMSG): Guidelines for the investigation of newly detected M-proteins and the management of monoclonal gammopathy of undetermined significance (MGUS). Br J Haematol 147: 22-42, 2009.

14. Dimopoulos MA, Kyle R, Fermand JP, Rajkumar SV, San Miguel J, Chanan-Khan A, Ludwig H, Joshua D, Mehta J, Gertz M, et al; International Myeloma Workshop Consensus Panel 3: Consensus recommendations for standard investigative workup: Report of the International Myeloma Workshop Consensus Panel 3. Blood 117: 4701-4705, 2011

15. Mead GP, Carr-Smith HD, Drayson MT, Morgan GJ, Child JA and Bradwell AR: Serum free light chains for monitoring multiple myeloma. Br J Haematol 126: 348-354, 2004.

16. Siegel D, Bilotti E and van Hoeven KH: Serum free light chain analysis for diagnosis, monitoring, and prognosis of monoclonal gammopathies. Lab Med 40: 363-366, 2009.

17. Smith A, Wisloff F and Samson D; UK Myeloma Forum; Nordic Myeloma Study Group; British Committee for Standards in Haematology: Guidelines on the diagnosis and management of multiple myeloma 2005. Br J Haematol 132: 410-451, 2006.

18. Donato LJ, Zeldenrust SR, Murray DL and Katzmann JA: A 71-year-old woman with multiple myeloma status after stem cell transplantation. Clin Chem 57: 1645-1648, 2011.

19. Fulton RB and Fernando SL: Serum free light chain assay reduces the need for serum and urine immunofixation electrophoresis in the evaluation of monoclonal gammopathy. Ann Clin Biochem 46 407-412, 2009

20. Vernocchi A, Gelsumini S and Piazza E: Prevalence of the monoclonal gammopathy of undetermined significance (MGUS) in out-patients $>50$ years old: An indication to carry out electrophoresis of serum protein? Biochim Clin 38 : $154-155,2014$
21. Gertz MA: Utility of the immunoglobulin free light chain assay for plasma cell disorders 2015. Leuk Lymphoma 56: 2757-2758, 2015

22. Bradwell AR, Carr-Smith HD, Mead GP, Harvey TC and Drayson MT: Serum test for assessment of patients with Bence Jones myeloma. Lancet 361: 489-491, 2003.

23. Drayson M, Tang LX, Drew R, Mead GP, Carr-Smith H and Bradwell AR: Serum free light-chain measurements for identifying and monitoring patients with nonsecretory multiple myeloma. Blood 97: 2900-2902, 2001.

24. Brioli A, Giles H, Pawlyn C, Campbell JP, Kaiser MF, Melchor L, Jackson GH, Gregory WM, Owen RG, Child JA, et al: Serum free immunoglobulin light chain evaluation as a marker of impact from intraclonal heterogeneity on myeloma outcome. Blood 123: 3414-3419, 2014.

25. Katzmann JA and Rajkumar SV: A window into immunoglobulin quantitation and plasma cell disease: Antigen epitopes defined by the junction of immunoglobulin heavy and light chains. Leukemia 27: 1-2, 2013.

26. Ludwig H, Milosavljevic D, Zojer N, Faint JM, Bradwell AR, Hübl W and Harding SJ: Immunoglobulin heavy/light chain ratios improve paraprotein detection and monitoring, identify residual disease and correlate with survival in multiple myeloma patients. Leukemia 27: 213-219, 2013.

27. Lakomy D, Lemaire-Ewing S, Denimal D, Bastie JN, Lafon I and Caillot D: Evaluation of the new Hevylite ${ }^{\mathrm{TM}} \operatorname{IgA}$ assay for the diagnosis and follow-up of monoclonal gammopathies. Ann Biol Clin (Paris) 71: 157-163, 2013 (In French).

28. Keren DF: Heavy/light-chain analysis of monoclonal gammopathies. Clin Chem 55: 1606-1608, 2009.

29. Astolfi M, Omedè P, Redoglia V, Oddolo D, Ferrero MP and Ciaiolo C: Simultaneous evaluation of serum Hevylite and Freelite assays for relapse prediction in multiple myeloma. Biochim Clin 37: 383-388, 2013.

30. Bhutani M, Landgren O and Usmani SZ: Multiple myeloma: Is it time for biomarker-driven therapy? Am Soc Clin Oncol Educ Book 35: e493-e503, 2015.

31. Landgren $\mathrm{O}$ and Morgan GJ: Biologic frontiers in multiple myeloma: From biomarker identification to clinical practice. Clin Cancer Res 20: 804-813, 2014

32. Paolini L, Di Noto G, Maffina F, Martellosio G, Radeghieri A, Luigi C and Ricotta D: Comparison of Hevylite ${ }^{\mathrm{TM}} \operatorname{IgA}$ and IgG assay with conventional techniques for the diagnosis and follow-up of plasma cell dyscrasia. Ann Clin Biochem 52: 337-345, 2015

33. Katzmann JA, Willrich MA, Kohlhagen MC, Kyle RA, Murray DL, Snyder MR, Rajkumar SV and Dispenzieri A: Monitoring IgA multiple myeloma: Immunoglobulin heavy/light chain assays. Clin Chem 61: 360-367, 2015.

34. Bradwell A, Harding S, Fourrier N, Mathiot C, Attal M, Moreau P, Harousseau JL and Avet-Loiseau H: Prognostic utility of intact immunoglobulin $\mathrm{Ig}^{\prime} \kappa / \mathrm{Ig}^{\prime} \lambda$ ratios in multiple myeloma patients. Leukemia 27: 202-207, 2013.

35. Koulieris E, Panayiotidis P, Harding SJ, Kafasi N, Maltezas D, Bartzis V, Tzenou T, Dimou M, Georgiou G, Mirbahai L, et al: Ratio of involved/uninvolved immunoglobulin quantification by Hevylite ${ }^{\mathrm{TM}}$ assay: Clinical and prognostic impact in multiple myeloma. Exp Hematol Oncol 1: 9, 2012.

36. Rajkumar SV, Landgren O and Mateos MV: Smoldering multiple myeloma. Blood 125: 3069-3075, 2015. 